Göthman, B. \& OHLsson, W.T.L. (1959) Fever with haematologic changes resembling infectious mononucleosis as a sequel of blood vessel grafting. Angiology, 10, 355.

Hager, E.B. \& Merrill, J.P. (1963) Peritoneal dialysis and acute renal failure. Surg. Clin. N. Amer. 43, 883.

Horton, E.H. (1966) Infectious mononucleosis-like syndrome after transfusion. Brit. med. J. i, 1419.

KäÄriänen, L., Klemola, E. \& Paloheimo, J. (1966) Rise of cytomegalovirus antibodies in an infectious mononucleosis-like syndrome after transfusion. Brit. med. J. i, 1270.
MAHER, J.F. \& SChreiner, G.E. (1967) The dialysis of poisons and drugs. Trans. Amer. Soc. artif. intern. Organs, 13, 369.

Smith, D.E. (1964) A syndrome resembling infectious mononucleosis after open heart surgery. Brit. med. J. i, 945.

TANAKA, K.R. (1964) Infectious mononucleosis syndromes. Brit. med. J. ii, 122.

Wheeler, E.O., Turner, J.D. \& Scannel, J.G. (1962) Fever, splenomegaly and atypical lymphocytes. A syndrome observed after cardiac surgery utilizing a pump oxygenator. New Engl. J. Med. 266, 454.

\title{
Endocarditis parietalis fibroplastica (Loffler's disease)
}

\author{
R. C. JenNings \\ M.D.(Lond.), L.M.S.S.A., M.C.Path., Dip.Path. \\ Consultant Pathologist
}

\author{
C. D. R. Pengelly \\ M.D.(Brist.), M.R.C.P., M.R.C.P.E. \\ Consultant Physician
}

North and Mid-Cheshire Hospitals

\section{Summary}

A case of endocarditis parietalis fibroplastica (Löffler's disease) is described and the aetiology and pathogenesis briefly discussed. Some of the relevant literature is reviewed.

\section{Introduction}

Endocarditis parietalis fibroplastica is a rare fatal disease of unknown aetiology in which there is a progressive subendocardial mural fibrosis. It is associated with a peripheral blood eosinophilia sometimes of leukaemoid proportions.

\section{Case report}

J.W., a gas fitter aged 20, was admitted for investigation to the Grange Hospital, Weaverham, on 27 April 1966 with a history of cough, morning wheezing and a little green sputum for 6 months. He complained of breathlessness on exertion and had lost 2 stones in weight and had occasional vomiting. He had never been abroad.

On examination he was pale and had a lowgrade pyrexia. There were poor basal breath sounds in the chest and scanty rales. His heart was slightly enlarged with a soft apical systolic murmur. Blood pressure was $160 / 110 \mathrm{mmHg}$. The spleen and liver were both palpable about $\frac{1}{2}$ in. below the costal margin. Urine contained albumin ++ and a trace of sugar.

\section{Investigations}

X-ray chest: bilateral small.pleural effusions and some diffuse shadows in both lungs. Vital capacity 2.34 litres (predicted from height and weight: 4.92 litres). FEV $_{1} 74 \%$, not improved by isoprenaline inhalation. ECG showed flattening of $\mathrm{T}$ waves in leads III, aVF and $\mathrm{V} 4,5$ and $6 . \mathrm{Hb}, 8.6 \mathrm{~g} / 100 \mathrm{ml}$; PCV, 32\%, MCHC, $27 \%$; ESR $33 \mathrm{~mm}$ in the 1st hour (Wintrobe); WBC, $35,000 / \mathrm{mm}^{3}$ (neutrophils $20 \%$, lymphocytes $9 \%$, monocytes $3 \%$, eosinophils $68 \%$ ) ; platelets $184,000 / \mathrm{mm}^{3}$; direct Coombs' test negative; leucocyte alkaline phosphatase: low score. Sternal marrow; normal cellularity; normoblastic erythropoiesis with a marked increase of eosinophils and their precursors. The appearances were those of an eosinophilic hyperplasia. LE cells not found, Rose-Waaler test negative, blood sugar $80 \mathrm{mg} / 100 \mathrm{ml}$, serum electrolytes and liver function tests normal. Serum proteins: albumin $4.5 \mathrm{~g} / 100 \mathrm{ml}$; globulin $3.0 \mathrm{~g} / 100 \mathrm{ml}$; electrophoresis: slight increase in $\gamma$-globulin. Stools for occult blood (four tests) positive. Sputum culture: normal flora. Urine deposit: red cells ++ , leucocytes + . Two blood cultures sterile. Mantoux test $1 / 1000$ positive. Precipitin test for trichinosis negative. Needle biopsy of the liver showed scattered eosinophils throughout the parenchyma with larger groups of similar cells mainly in the portal tracts.

A provisional diagnosis of polyarteritis nodosa was made and oral treatment with prednisolone $10 \mathrm{mg}$ t.d.s. was started: this was gradually reduced to $7.5 \mathrm{mg}$ t.d.s. and a course of erythromycin was given. He improved a little, his breathlessness lessened and he was discharged from hospital on 23 May 1966. Late in June he developed further cardiac enlargement and a protodiastolic gallop at the apex; his spleen and liver were both palpable 2 in. below the costal 
margin. The white cells were $23,000 / \mathrm{mm}^{3}$ with $65 \%$ eosinophils and the $\mathrm{Hb}$ was $10 \cdot 8 \mathrm{~g} / 100 \mathrm{ml}$. During the next 3 months he developed congestive heart failure and was re-admitted to hospital on 1 September at which time his white cells were $34,500 / \mathrm{mm}^{3}$, with $88 \%$ eosinophils. Treatment with digoxin and frusemide improved him and his prednisolone was reduced to $5 \mathrm{mg}$ t.d.s. Blood pressure was $140 / 80 \mathrm{mmHg}$. He deteriorated again and by 15 December 1966 was in severe heart failure, had developed a thrombosed right external jugular vein and haemoptysis presumed due to pulmonary embolism. He was treated with anticoagulants and his prednisolone was increased to $10 \mathrm{mg}$ t.d.s. A course of cyclophosphamide was started but he rapidly deteriorated and died on 22 January 1967.

\section{Necropsy findings (48 hr after death)}

The body was that of a well-covered young man showing marked bilateral leg oedema. There were small bilateral straw-coloured pleural effusions and both lungs showed marked generalized oedema with thickening of the interlobular septa. Several small infarcts were present in the lower lobes, with evidence of emboli in

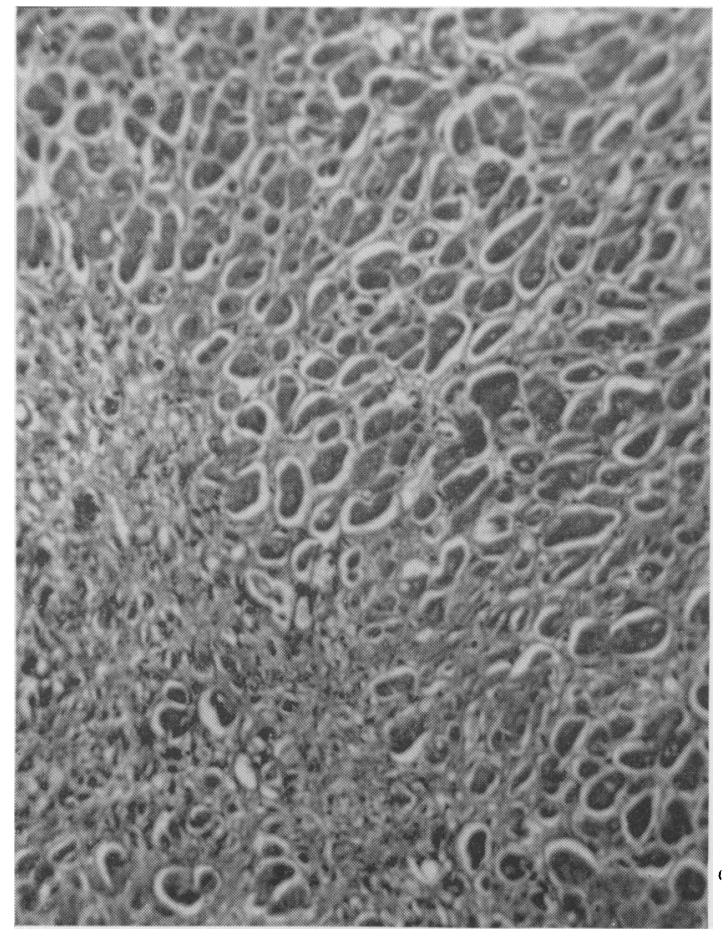

Fig. 1. Left ventricle showing extensive mural fibrosis. van Gieson, $\times 50$. the arteries supplying these segments. The heart was enlarged $(630 \mathrm{~g})$ due to hypertrophy of the left ventricle. There was diffuse myocardial fibrosis involving both ventricles with attached mural thrombus overlying a fibrotic area at the apex of the left ventricle. The valves were normal but there was prominent subendocardial fibrosis of both ventricles and left atrium and to a lesser degree the right atrium. The liver was grossly enlarged $(3000 \mathrm{~g})$ with a prominent nutmeg appearance. The spleen was also enlarged (575 g) and showed a firm congested appearance. The pancreas showed a small softened yellowish lesion $1 \mathrm{~cm}$ across within the central part of the head; the remainder was normal. All other organs were of normal appearance.

\section{Histological examination}

Widespread mural fibrosis was present in the left ventricle (Fig. 1) with similar less-marked lesions in the right ventricle and in both atria. Subendocardial fibrosis was present in all chambers. This was most marked in the left atrium (Fig. 2) and left ventricle, the latter showing some vascular granulation tissue beneath the mural thrombus at the apex. There was a slight
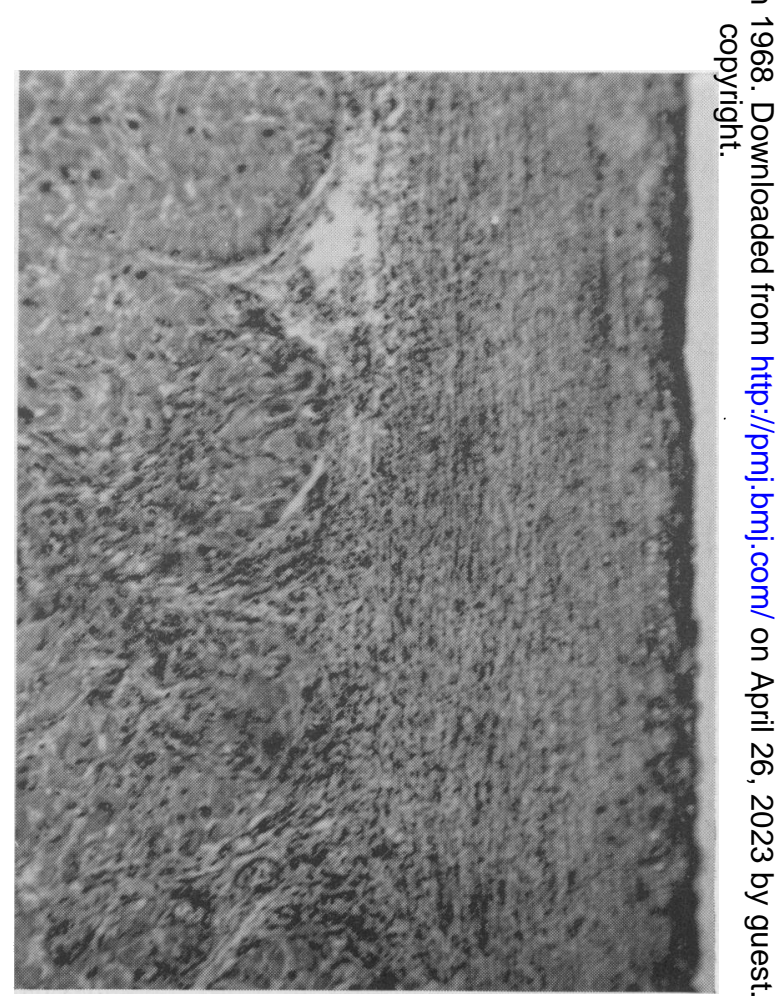

Fig. 2. Subendocardial fibrosis left atrium. Verhoeff's elastic van Gieson, $\times 25$. 
increase of fibrous tissue beneath the endocardium in the right ventricle and right atrium. Elastic fibres were slightly increased in the subendocardial fibrous tissue in the left atrium (Fig. 2) but not in the other chambers of the heart. The pericardium was normal. The lungs showed oedema and an increase of loose connective tissue in the interlobular septa (Fig. 3). Infarcts were present in the lungs but there was no evidence of any arteritis. The liver showed gross congestion with centrilobular necrosis and capsular thickening. A few scattered eosinophils were seen, mainly in the portal tracts, but nowhere were there any large groups of these. The bone marrow showed an excess of eosinophils and precursors, but the picture was not of leukaemic type. The pancreas showed a single small area of necrosis with a cellular exudate containing mainly polymorphs and eosinophils. The remainder of the organs were within normal limits. Apart from the small numbers of eosinophils in the liver there was no evidence of eosinophilic infiltration of other organs. No arteritis was seen in any of the small arteries.

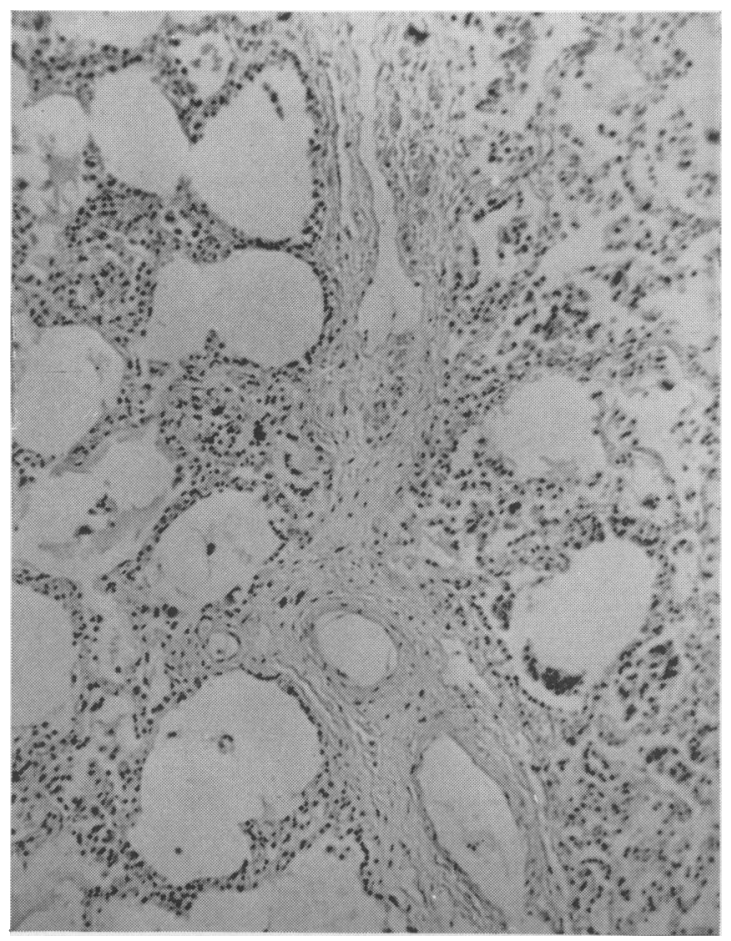

FIG. 3. Lung showing fibrosis of interlobular septa. $\mathrm{H} \& \mathrm{E}, \times 25$.

\section{Discussion}

Löffler (1936) described two cases which he called endocarditis parietalis fibroplastica and since this original report less than fifty similar cases have been recorded in the literature. The two essential requisites for a diagnosis of this condition are a fibrosing mural endocarditis and a blood eosinophilia. Weiss-Carmine (1957) comprehensively reviewed the condition and Brink \& Weber (1963) added three more of their personally studied cases to the thirty-seven previously reported instances in the literature. Since then only single case reports have appeared (Mautner \& Harris, 1966). The majority of these reports have been from Continental Europe, with only a few from Africa, the U.K., U.S.A. and Canada. The disease occurs predominantly in young males (Weiss-Carmine, 1957) with mainly an acute or subacute onset, often with initial symptoms referable to the respiratory tract, particularly dyspnoea and wheezing. Subsequently cardiac symptoms have developed in all cases leading to progressive congestive failure. Symptoms due to embolism from mural thrombi in the ventricles have been common and an embolic nephritis has been described (Saphir, 1958).

ECG findings are usually non-specific, consisting of changes in the S-T segments and $T$ waves, though a ' $P$ pulmonale' was present in the case described by Lennox (1948).

The eosinophilia, although variable, is an essential component of the disease. It may reach leukaemoid proportions with total eosinophil counts of over $100,000 / \mathrm{mm}^{3}$ (Wiener \& Knights, 1957). The marrow reflects the peripheral blood picture with eosinophilic predominance but there is never leukaemic immaturity of the myeloid series. In some instances cases of so-called 'eosinophilic leukaemia' terminating in congestive failure and showing myocardial cellular infiltrates are possibly examples of Löffler's disease (Englefeldt \& Zetterström, 1956). Pierce, Hosseinian \& Constantine (1967) also suggest that disseminated eosinophilic 'collagen disease' (Englefeldt \& Zetterström, 1956) may be the same as Löffler's disease, but their case did not show any endocardial abnormality.

The organ mainly affected in Löffler's disease is the heart, with lung involvement in some cases. There is an initial mainly eosinophilic infiltration in the subendocardium and myocardium, which progresses to a subendocardial and mural fibrosis. As the fibrosis develops the cellular elements decrease and in the later stages of the disease only a few scattered eosinophils are found. All chambers of the heart may be involved either individually or together and pro- 
gressive cardiac enlargement usually occurs. Mural thrombi overlying damaged endocardium are common and embolic lesions from these may result. There is never a true valvular endocarditis although fibrosis of the papillary muscles or chordae tendineae may lead to incompetence of the mitral and the tricuspid valves (Brink \& Weber, 1963). The subendocardial fibrosis which is the essential feature of this condition produces a pearly-white thickening of the endocardium which histologically consists of fibrous tissue with little or no increase in elastic fibres. No true vascular lesions of polyarteritic type are found.

It is possible that Löffler's Syndrome (Löffler, 1932) is the benign counterpart of this condition, the lung involvement being self-limiting and the heart escaping damage. In our case pulmonary infiltration was present at an early stage of the disease and it is possible that this resulted in the interlobular fibrosis found at necropsy. It is interesting that the marked eosinophilic infiltration in the biopsy specimen of liver was not present in the necropsy sections. These appearances were so striking in life that the possibility of a leukaemic infiltration was considered, but this interpretation was not supported by the marrow findings. The disappearance of the infiltration as part of the natural progression of the disease seems likely, and Hoffman, Rosenbaum \& Genovese (1955) found a normal liver biopsy in their patient despite a pronounced blood eosinophilia.

The aetiology of Löffler's disease is unknown. On the basis of the eosinophilia an allergic mechanism is usually assumed. Whether the eosinophilic infiltration has a fibrogenic effect on the endocardium and myocardium or whether the fibrosis is the direct result of an underlying pathogenic agent is not clear. The possibility of a self-perpetuating autoimmune process following primary damage to the heart cannot be excluded.

\section{References}

BRINK, A.J. \& WEBER, H.W. (1963) Fibroplastic parietal endocarditis with eosinophilia. Löffler's endocarditis. Amer. J. Med. 34, 52.

ENGLEFELDT, B. \& ZetTerström, R. (1956) Disseminated eosinophilic collagen disease. Acta med. scand. 153, 337.

Hoffman, F.G., Rosenbaum, D. \& Genovese, P.D. (1955) Fibroplastic endocarditis with eosinophilia (Löffler's endocarditis parietalis fibroplastica). Case report and review of literature. Ann. intern. Med. 42, 668.

LENNOX, B. (1948) Acute parietal endocarditis in a case of status asthmaticus. A possible early stage of Löffler's endocarditis parietalis fibroplastica with eosinophilia. J. Path. Bact. 60, 621

LöfFLER, W. (1932) Zur Differential-Diagnose der Lungeninfiltrierungen. II. Uber Flüchtige Succedan-Infiltrate (mit Eosinophilie). Beitr. z. Klin. Tuberk. 79, 368.

LöFFLER, W. (1936) Endocarditis parietalis fibroplastica mit Bluteosinophilie. Schweiz. med. Wschr. 66, 817.

MAUTNER, L.S. \& HARRIS, F. (1966) Fibrosing endocarditis with eosinophilia. Canad. med. Ass. J. 95, 1201.

Pierce, L.E. Hosseinian, A.H. \& Constantine, A.B. (1967) Disseminated eosinophilic collagen disease. Blood, 29, 540.0

SAPHIR, O. (1958) A Text on Systemic Pathology, Vol. 1 p. 58. Grune \& Stratton, New York and London.

WeIss-CARMINE, S. (1957) Die Endocarditis parietalis fibroplastica mit Bluteosinophilie (Löffler) und ihre Stellung im Rahmen der Parietalendokardifibrosen. Schweiz. med. Wschr. 87, 890.

WIENER, M.J. \& KNIGHTS, E.M. (1957) Löffler's endocarditis parietalis fibroplastica with eosinophilia. Amer. Heart $J$. 53, 157.

\title{
Tricuspid incompetence due to right ventricular papillary muscle dysfunction
}

\author{
ANNE E. TATTERSFIELD \\ M.B., B.S., M.R.C.P. \\ Medical Registrar, Cardiothoracic Department, \\ Central Middlesex Hospital
}

\section{Summary}

There has recently been much interest in mitral incompetence as a result of papillary muscle damage in myocardial infarction. We report a case of tricuspid incompetence due to papillary muscle dysfunction following myocardial infarction involving the right ventricle.

\section{Case report}

A 61-year-old male office worker was ad- mitted to the Coronary Care Unit at Central Middlesex Hospital in April 1967 with a typical history of myocardial infarction. In 1961 his blood pressure had been noted to be $210 / 120$ $\mathrm{mmHg}$ but he had no past history of ischaemic or rheumatic heart disease.

On admission his pain had disappeared and he was neither cyanosed nor dyspnoeic, with warm extremities. The pulse was regular $(80 / \mathrm{min})$ apart from 1:5 ectopic beats and his blood 